\title{
SYNTHESIS, STRUCTURAL CHARACTERIZATION AND ANTIMICROBIAL STUDIES OF NOVEL SCHIFF BASE COPPER(II) COMPLEXES
}

\author{
N. RAMAN*, J. JOSEPH, A. SAKTHIVEL and R.JEYAMURUGAN \\ Research Department of Chemistry, VHNSN College, Virudhunagar-626 001, India.
}

(Received: November 20, 2008 - Accepted: August 17, 2009)

\begin{abstract}
Five novel copper(II) complexes have been synthesized using Schiff base ligands, synthesized by the condensation reaction of anthranilic acid and Knoevenagel $\beta$-ketoanilide condensates (obtained by the condensation of acetoacetanilide and substituted benzaldehydes). The ligands and copper(II) complexes have been characterized on the basis of Microanalytical, Mass, UV-Vis., IR, ${ }^{1} \mathrm{H}$ NMR, ESR, XRD and CV spectral studies, as well as magnetic susceptibility and conductivity data. On the basis of spectral studies, a square-planar geometry has been proposed for the copper(II) complexes. From the XRD data, the CuL ${ }^{1}$ complex has the crystallite size of $50 \mathrm{~nm}$ respectively. The in vitro antimicrobial activity of the compounds is tested against the bacteria Escherichia coli, Salmonella typhi, Staphylococcus aureus, Klebsiella pneumoniae and Pseudonomas aeruginosa and fungi Aspergillus niger, Rhizopus stolonifer, Aspergillus flavus, Rhizoctonia bataicola and Candida albicans by well diffusion method. The complexes show stronger antimicrobial activity than the free ligands. They represent a novel class of metal-based antimicrobial agents which provide opportunities for a large number of synthetic variations for modulation of the activities.
\end{abstract}

Keywords: Schiff base ligands, square-planar, Knoevenagel.

\section{INTRODUCTION}

Drug resistance has become a growing problem in the treatment of infectious diseases caused by bacteria, fungi, parasite and virus. Infectious diseases like diarrhoea, dysentery, tuberculosis, acute respiratory tract infections, AIDS and recently SARS are global threat and their incidences are increasing significantly day by day. Although a number of chemotherapeutic agents are available in market places, the pathogenic organisms are developing resistance to these agents. So, it is important to find out safer, more effective and inexpensive chemotherapeutic agents.

Metals have an esteemed place within medical biochemistry, although until recently this has been restricted predominantly to organic drugs. Recently however, more research has been done in the area of inorganic chemistry, which has led to developments in cancer care, infection control, diabetes, ulcers and neurological, cardiovascular and anti-inflammatory drugs. Metal coordination complexes have been widely studied for their antimicrobial ${ }^{1,2}$ and anticancer properties ${ }^{3}$. Many drugs possess modified pharmacological and toxicological properties when administered in the form of metallic complexes. Platinum anticancer drugs are now the widely used anticancer drugs in the world e.g. cisplatin, carboplatin, oxaliplatin, tetraplatin etc. This inspires synthetic chemists to search for new metal complexes for bioactive compounds and copper in particular has attracted the researchers. Probably the most widely studied cation in this respect is $\mathrm{Cu}^{2+}$, since a host of low-molecular-weight copper complexes have been proven beneficial against several diseases such as tuberculosis, rheumatoid, gastric ulcers and cancers ${ }^{4,5}$. Metal complexes of copper containing nitrogen and oxygen donor ligands are found to be effective catalysts for oxidation of olefins, etc. The coordination environment around copper plays the key role in stabilizing its different oxidation states and hence dictates the redox properties of the central atoms. The treatment with copper complexes produces remarkable pharmacological effects, which are not observed when the parent ligands or inorganic forms of copper are used ${ }^{6}$. Various copper complexes have been reported to inhibit bacterial, fungal, yeast, algal, mycoplasma, and viral growth, as well as to cause the death of these organisms ${ }^{7-9}$.

This prompted us to investigate some novel copper(II) complexes using Schiff base ligands. For, the coordination chemistry of Schiff base ligands is of considerable interest due to their biological importance ${ }^{10-12}$. A literature search revealed that no work has been done on the Schiff base ligands having anthranilic acid and Knoevenagel condensed $\beta$-ketoanilides. Hence, in this paper we describe the synthesis of these ligands. Further insight into the bonding and possible geometrical structure has been made by Microanalytical, Mass, IR, UV-Vis., ${ }^{1} \mathrm{H}$ NMR, ESR,XRD and CV spectral studies, as well as magnetic and conductivity data. The in vitro antimicrobial activity of the compounds is also tested against few bacteria and fungi.

\section{EXPERIMENTAL}

All reagents were of Merck products and used as supplied. For the voltammetric experiments, tetrabutylammoniumperchlorate (TBAP) used as supporting electrolyte, was purchased from Sigma. Anhydrous grade methanol and DMSO were obtained from Fisher Scientific Company. Micro analytical data and FAB Mass spectra of the compounds were recorded at the Sophisticated Analytical Instrumentation Facility, Central Drug Research Institute (SAIF, CDRI), Lucknow. The FAB mass spectrum of the complex was recorded on a JEOL SX 102/DA-6000 mass spectrometer/data system using argon/xenon $(6 \mathrm{kV}, 10 \mathrm{~mA})$ as the FAB gas. The accelerating voltage was $10 \mathrm{kV}$ and the spectra were recorded at room temperature using $m$-nitrobenzylalcohol (NBA) as the matrix. The IR spectra of the samples were recorded on a Shimadzu FTIR-8400S spectrophotometer in $4000-400 \mathrm{~cm}^{-1}$ range in a $\mathrm{KBr}$ pellet. The UV-Vis. spectra were recorded on a Shimadzu UV-1601 spectrophotometer. Magnetic susceptibility measurements of the complexes were carried out by Gouy balance using copper sulphate as the calibrant. The values were corrected for diamagnetism by applying Pascal's constants. Electrochemical studies were carried out using BAS CV-50 cyclic voltammogram. CV measurements were performed using a glassy carbon working electrode, platinum wire auxiliary electrode and an $\mathrm{Ag} / \mathrm{AgCl}$ reference electrode. All solutions were purged with $\mathrm{N}_{2}$ for 30 min prior to each set of experiments. The molar conductance of the complexes was measured using Systronic conductivity bridge. The $400 \mathrm{MHz}$ ${ }^{1} \mathrm{H}$ NMR spectra of the Schiff bases and their zinc complexes were recorded at Indian Institute of Technology, Chennai. ESR spectra of the paramagnetic complexes were recorded at liquid nitrogen temperature as a corresponding class in the X-band region on a Varian E-112 spectrometer equipped with $100 \mathrm{kHz}$ field modulation at IIT, Chennai. The computer controlled X-ray diffractometer system JEOL JDX 8030 was used to record the data for powder copper complex, recorded at Central Electrochemical Research Institute (CECRI), Karaikudi.

\section{In vitro antimicrobial activity}

In vitro antimicrobial assay was performed by well diffusion method. The complexes and ligands were tested against bacteria such as Escherichia coli, Klebsiella pneumoniae, Salmonella typhi, Pseudomonas aeruginosa and Staphylococcus aureus by the well diffusion method using nutrient agar as the medium and fungi such as Aspergillus niger, Rhizopus stolonifer, Aspergillus flavus, Rhizoctonia bataicola and Candida albicans, cultured on potato dextrose agar as medium. In a typical procedure, a well was made on the agar medium inoculated with the microorganisms. The well was filled with the test solution using a micropipette and the plate was incubated at $30^{\circ} \mathrm{C}$ for $72 \mathrm{~h}$. During this period, the test solution diffused and the growth of the inoculated microorganisms was affected. The inhibition zone developed on the plate was measured. The inhibition zone developed on the plate was measured. The MIC of the complexes was determined by serial dilution technique ${ }^{13}$. 


\section{Syntheses of Schiff base ligands}

\section{Synthesis of Knoevenagel condensate $\beta$-ketoanilide}

Condensation of acetoacetanilide with $m$-nitrobenzaldehyde $\left(\mathrm{L}^{1}\right) / o$ chloro benzaldehyde $\left(\mathrm{L}^{2}\right) /$ benzaldehyde $\left(\mathrm{L}^{3}\right) / p$-methoxybenzaldehyde $\left(\mathrm{L}^{4}\right)$ / $p$-hydroxy benzaldehyde $\left(\mathrm{L}^{5}\right)$ was performed by heating equimolar amounts $(10$ mmol) under reflux in $50 \mathrm{~mL}$ ethanol, in the presence of 5 drops of piperidine as the catalyst for $c a .5 \mathrm{~h}$. The solution was then cooled and the condensed product was separated by adding $5 \mathrm{~mL}$ of toluene and $30 \mathrm{ml}$ of petroleum ether $\left(40-60^{\circ} \mathrm{C}\right)$. The yellow coloured solid (Knoevengal b-ketoanilide condensate) was isolated by filtration, washed and recrystallised from ethanol.

\section{Synthesis of Schiff bases}

Knoevenagel $\beta$-ketoanilide condensate(s) $(10 \mathrm{mmol})$ was dissolved in ethanol $(30 \mathrm{~mL})$ and refluxed with anthranilic acid $(20 \mathrm{mmol})$ in ethanol $(20 \mathrm{~mL})$ with the addition $1 \mathrm{~g}$ of anhydrous $\mathrm{K}_{2} \mathrm{CO}_{3}$ for $c a .6 \mathrm{~h}$. The solvent was reduced to one-third and the pasty mass so obtained was treated with hot water and set aside in refrigerator for $c a .10 \mathrm{~h}$. The solid material formed was removed by filtration and recrystallised from ethanol.

\section{Synthesis of metal complexes}

A solution of Schiff base ligand(s) $(5 \mathrm{mmol})$ in ethanol $(20 \mathrm{~mL})$ was added to a solution of copper chloride $(5 \mathrm{mmol})$ in ethanol $(10 \mathrm{~mL})$ and the mixture was refluxed for $6 \mathrm{~h}$ and concentrated to one-third volume and kept at $0^{\circ} \mathrm{C}$ for $2 \mathrm{~h}$. The solid product formed was filtered, washed with ethanol and dried in vacuo.

\section{RESULTS AND DISCUSSION}

All the complexes are stable at room temperature, insoluble in water but soluble in DMSO and chloroform. The physical properties and analytical data of the complexes are given in Table 1. The elemental analysis data of the complexes are in good agreement with theoretical values. These complexes showed lower conductance values $\left(5-20 \mathrm{ohm}^{-1} \mathrm{~cm}^{2} \mathrm{~mol}^{-1}\right)$ indicating their non-electrolytic nature. The magnetic moments (Table 1) of all the $\mathrm{Cu}$ (II) complexes under the present study were found to be in the range of 1.79-1.86 B.M. at room temperature, suggesting monomeric nature of the complexes ${ }^{14}$.

\section{Mass spectra}

The fast atom bombardment mass spectrum of the Schiff base $\left(\mathrm{L}^{1}\right)$ showed a peak at $\mathrm{m} / \mathrm{z} 549\left[\mathrm{M}^{+}\right]$, as expected for a monomeric formulation of the respective ring. Its $\mathrm{CuL}^{1}$ complex exhibited a peak at $\mathrm{m} / \mathrm{z} 610\left[\mathrm{M}^{+}\right]$, which confirms the stoichiometric composition of the complex formation. This is also supported by the FAB mass spectra of the other complexes. Elemental analysis values are in close agreement with the values calculated from molecular formula assigned to these complexes, which is further supported by the FABmass studies of representative complexes.

\section{IR spectra}

The spectra of free ligands show a band in the region $1625-1610 \mathrm{~cm}^{-1}$ characteristics of the $v_{\mathrm{C}=\mathrm{N}}$ (azomethine) stretching mode ${ }^{15-17}$ indicating the formation of the Schiff base products. This band is shifted towards lower frequencies in the spectrum of its copper complex 1596-1578 cm-1 compared with the above Schiff bases indicating the involvement of the azomethine nitrogen in chelation with the copper ion, the coordination of nitrogen to the copper ion would be expected to reduce the electron density of the azomethine link and thus cause a shift in the $v_{\mathrm{C}=\mathrm{N}}$ group $^{18}$. The intense band at $1694-1668 \mathrm{~cm}^{-1}$ present in the IR spectra of the free ligands may be assigned to the $v_{\text {co }}$ (carboxylic group), similar band was observed at the same frequency region in the IR spectra of some organic acid ligands ${ }^{19,20}$. However, the spectra of all complexes show the absence of this band accompanied by the appearance of two characteristic bands at $1632-1600$ and $1402-1346 \mathrm{~cm}^{-1}$ attributed to $v_{\text {asy }}\left(\mathrm{COO}^{-}\right)$and $v_{\text {sy }}\left(\mathrm{COO}^{-}\right.$ ), respectively, indicating the participation of the carboxylate oxygen atom in the complexes formation. The mode of coordination of carboxylate group has often been deduced from the magnitude of the observed separation between the $v_{\text {asym }}\left(\mathrm{COO}^{-}\right)$and $v_{\text {sym }}\left(\mathrm{COO}^{-}\right)$, the separation value between $v_{\text {asym }}\left(\mathrm{COO}^{-}\right)$ and $v\left(\mathrm{COO}^{-}\right)$in metal complexes was more than $200 \mathrm{~cm}^{-1}\left(266-212 \mathrm{~cm}^{-1}\right)$ suggests the coordination of carboxylate group in all copper complexes of the ligands in a monodentate fashion ${ }^{20-23}$

Conclusive evidence of the bonding is also shown by the observation that new bands in the spectra of all metal complexes appear in the low frequency regions at $410-442 \mathrm{~cm}^{-1}$ and $454-478 \mathrm{~cm}^{-1}$ characteristic to $v_{(\mathrm{M}-\mathrm{N})}$ and $v_{\mathrm{M}-\mathrm{O} \text { carbo }}$ stretching vibrations, respectively, that are not observed in the spectra of free ligands ${ }^{24,25}$

\section{Electronic spectra}

The electronic absorption spectra of $\mathrm{L}^{1} / \mathrm{L}^{2} / \mathrm{L}^{3} / \mathrm{L}^{4} / \mathrm{L}^{5}$ and their copper complexes were recorded at $300 \mathrm{~K}$ using suitable solvent. The solvent, absorption region, assignment of the absorption bands and the proposed geometry of the complexes are given in Table 2. From the table, we concluded that all the complexes are having square-planar geometry around the copper(II) ion.

The copper complexes are magnetically normal with a magnetic moment of 1.79-1.86 B.M. These complexes show a d-d transition nearly at $500 \mathrm{~nm}$ which can be assigned as ${ }^{2} \mathrm{~B}_{\mathrm{g}}{ }^{\circledR} \mathrm{A}^{2}$ transition, reveals that these copper(II) complexes exist in square-planar geometry ${ }^{25,26}$. The absence of absorption below $1000 \mathrm{~nm}$ excludes the possibility of tetrahedral geometry for the complex (Figure 1).

\section{${ }^{1} \mathrm{H}$ NMR spectra}

${ }^{1} \mathrm{H}$ NMR spectrum of the ligand $\mathrm{L}^{1}$ recorded in $\mathrm{CDCl}_{3}$ solution. It shows a singlet at $1.5 \mathrm{ppm}$ due to the methyl proton. Signals due to aromatic protons appear at 6.8-7.6 ppm The peaks at 8.2 and $10.8 \mathrm{ppm}$ are attributable to -NH(protons of acetoacetanilide moiety) and $-\mathrm{COOH}$ of anthranilic acid moiety. This is also supported by the ${ }^{1} \mathrm{H}$ NMR spectra of the other ligands.

\section{ESR spectra}

The ESR spectrum of the $\left[\mathrm{CuL}^{1}\right]$ was recorded in DMSO at 300 and $77 \mathrm{~K}$ (Figures 2 and 3). The frozen solution spectrum shows a well resolved four line spectrum and no features characteristic for a dinuclear complex. This is also supported by the magnetic moment of $\left[\mathrm{CuL}^{1}\right]$ (1.86 B.M.) which confirms the mono nuclear nature of the complex. The spin Hamiltonian parameters for the copper complex were calculated from the spectrum and are tabulated (Table 3). The observed order $g_{I I}>g_{\lambda}>g_{e}$ indicates that the complex is square planar. Further, it is supported from the fact that the unpaired electron lies predominantly in the $\mathrm{d}_{x-y}^{2}{ }^{2}$ orbital ${ }^{27-29}$. The value of exchange interaction term $\mathrm{G}$, estimated from the following expression is estimated as 4.5.

If $\mathrm{G}>4.0$, the local tetragonal axes are aligned parallel or only slightly misaligned. If $\mathrm{G}<4.0$, significant exchange coupling is present and the misalignment is appreciable. The observed value for the exchange interaction parameter for the copper complex $(G=4.5)$ suggests that significant exchange coupling is present and the misalignment is appreciable, and the unpaired electron is present in the $\mathrm{d}_{\mathrm{x}}^{2}{ }^{2}$ orbital. This result also indicates that the exchange coupling effects are not operative in the present complex ${ }^{30}$.

Massacesi et al. ${ }^{31,32}$ reported $\mathrm{g}_{\mathrm{JI}}$ values in the range 2.3-2.4 for complexes containing copper-oxygen bonds and 2.2-2.3 for complexes containing coppernitrogen bonds. The present copper complexes have $\mathrm{g}_{\mathrm{II}}=2.2-2.4$ in conformity with both $\mathrm{Cu}-\mathrm{O}$ and $\mathrm{Cu}-\mathrm{N}$ bonds in the copper complexes.

It is usual to determine the covalent bonding parameter for the $\mathrm{Cu}(\mathrm{II})$ ion in various ligand field environments. The simplified molecular orbital theory was adopted to calculate the bonding coefficients such as in-plane p-bonding $\left(\beta^{2}\right)$, out-of-plane p-bonding $\left(\gamma^{2}\right)$ and in-plane s-bonding $\left(\alpha^{2}\right)$. The in-plane s-bonding parameters, $\alpha^{2}$ are related to $g_{\|}$and $g_{\wedge}$ according to the following equation

$\alpha^{2}=-\left(\mathrm{A}_{\|} / 0.036\right)+\left(\mathrm{g}_{\|}-2.0036\right)+3 / 7\left(\mathrm{~g}_{\wedge}-2.0036\right)+0.04$

If the $\alpha^{2}$ value $=0.5$, it indicates a complete covalent bonding, while the value of $\alpha^{2}=1.0$ suggests a complete ionic bonding. The observed value $(0.892)$ indicates that the complexes have some covalent character. The outof-plane p-bonding $\left(\gamma^{2}\right)$ and in-plane p-bonding $\left(\beta^{2}\right)$ parameters are calculated from the following expressions:

$\beta^{2}=\left(\mathrm{g}_{-}-2.0036\right) \mathrm{E} /-81 \mathrm{a}^{2}$

$\gamma^{2}=\left(\mathrm{g}_{\wedge}-2.0036\right) \mathrm{E} /-2 \mathrm{a}^{2}$

The bonding parameters $\left(\alpha^{2}, \beta^{2}\right.$ and $\left.\gamma^{2}\right)$ of the copper complexes are calculated and summarized in Table 4 . From the above table, the $a^{2}, b^{2}$ and $\mathrm{g}^{2}$ values indicate that there is substantial interaction in the in-plane-bonding whereas both the in-plane and out-of-plane p-bonding coefficients are almost ionic. These results are anticipated because there are no appropriate ligand orbitals to combine with the $\mathrm{d}_{x y}$ orbital of copper(II) ion. The ' $p$ ' values for a complex containing $\mathrm{N}_{2} \mathrm{O}_{2}$ donor atoms fall in the range $0.022-0.029 \mathrm{~cm}^{-1}$. The p-values for the copper complexes are consistent with bonding of copper with nitrogen and oxygen donor atoms $\mathrm{s}^{33,34}$.

Based on the above spectral and analytical data, the proposed structure of the ligands and its copper complexes are shown in figure 4.

\section{Electrochemical behaviour}

The cyclic voltammogram of the $\mathrm{CuL}^{1}$ complex in acetonitrile solution at $300 \mathrm{~K}$ in the potential range +0.4 to $-0.8 \mathrm{~V}$ at scan rate $0.1 \mathrm{Vs}^{-1}$ was recorded and data of all the complexes were presented (Figure 5). It shows a welldefined redox process corresponding to the formation of the quasi-reversible $\mathrm{Cu}(\mathrm{II}) / \mathrm{Cu}(\mathrm{I})$ couple. The anodic peak at $\mathrm{Ep}=-0.15 \mathrm{~V}$ versus $\mathrm{Ag} / \mathrm{AgCl}$ and the associated cathodic peak at $\mathrm{Ep}_{\mathrm{c}}=-0.32 \mathrm{~V}$ correspond to the $\mathrm{Cu}(\mathrm{II}) / \mathrm{Cu}(\mathrm{I})$ couple. The $\left[\mathrm{CuL}^{1}\right]$ complex exhibits a quasi-reversible behaviour as indicated by the non-equivalent current intensity of cathodic and anodic peaks. The quasi-reversible behaviour of this complex is also supported by the presence of 
large peak separation of $\mathrm{Ep}_{\mathrm{a}}$ and $\mathrm{Ep}$.

\section{Antimicrobial activity}

The in vitro antimicrobial activity of the compounds was tested against the bacteria Escherichia coli, Salmonella typhi, Staphylococcus aureus, Klebsiella pneumoniae and Seudomonas aeruginosa and fungi Aspergillus niger, Rhizopus stolonifer, Aspergillus flavus, Rhizoctonia bataicola and Candida albicans by well diffusion method. The minimum inhibitory concentration (MIC) values of the compounds are summarized in Tables 5 and 6 . A comparative study of the ligand and its complexes (MIC values) indicates that complexes exhibit higher antifungal activity than the free ligand. From the MIC values (Tables 5 and 6), it was found that the compound $6, \mathrm{CuL}^{1}$ was more potent among the other investigated complexes and the standard. Further studies are required to explore these complexes as drugs.

Compounds containing $>\mathrm{C}=\mathrm{N}$ group have enhanced antimicrobial activity than $>\mathrm{C}=\mathrm{C}<$ group. The growth of certain microorganisms take place even in the absence of $\mathrm{O}_{2}$. Hence, compounds containing $>\mathrm{C}=\mathrm{C}<$ group through capable of absorbing $\mathrm{O}$ are not related with the growth of microorganisms.

Such increased activity of the complexes can be explained on the basis of Overtone's concept ${ }^{35}$ and Tweedy's Chelation theory ${ }^{36}$. According to Overtone's concept of cell permeability, the lipid membrane that surrounds the cell favours the passage of only the lipid-soluble materials makes which liposolubility is an important factor, which controls the antifungal activity. On chelation, the polarity of the copper ion will be reduced to a greater extent due to the overlap of the ligand orbital and partial sharing of the positive charge of the copper ion with donor groups. Further, it increases the delocalization of $\pi$-electrons over the whole chelate ring and enhances the lipophilicity of the complexes. This increased lipophilicity enhances the penetration of the complexes into lipid membranes and blocking of the metal binding sites in the enzymes of microorganisms. These complexes also disturb the respiration process of the cell and thus block the synthesis of the proteins that restricts further growth of the organism.

\section{Effect of substituents}

Generally, the nature (electron withdrawing and electron releasing substituents) and position of substituents present in the phenyl ring decide the antimicrobial activities. It is well known that the substituents at $o$-position have lower antimicrobial activity whereas the substituents at $m$ - and $p$-positions have higher antimicrobial activity. It is obvious that inhibitory action gets enhanced with the introduction of electron-withdrawing nitro and chloro groups in the phenyl ring. However, electron-releasing substituents such as methoxy and hydroxyl groups are lesser active compared to unsubstituted phenyl ring. The lower activity of complexes could also be accounted on the basis of low lipid solubility. Hence, the metal ion cannot reach the desirable site of action of the cell wall to interfere with the normal cell activity. The nature of metal ion also plays a decisive role in determining antifungal properties.

In the present study, the order of the antimicrobial activity of the synthesized compounds (based on the substituent present in the phenyl ring) is as follows:

$$
-\mathrm{NO}_{2}>-\mathrm{Cl}>-\mathrm{H}>-\mathrm{OCH}_{3}>-\mathrm{OH}
$$

Effect of hetero atoms

From the observation, the higher inhibition of microbial growth is due to uncoordinated hetero atoms and carboxylic moieties. In the complexes, the ligands have some uncoordinated donor atoms which enhance the activity of the complexes by bonding with trace elements present in microorganisms may combine with the uncoordinated site and may inhibit the growth of fungi.

The mode of action of the compounds may involve the formation of a hydrogen bond through the azomethine group $(>\mathrm{C}=\mathrm{N}-)$ with the active centers of cell constituents, resulting in interferences with the normal cell process ${ }^{37}$. Although the exact mechanism is not understood biochemically, mode of action of antimicrobials may involve various targets in microorganisms.

(i) Interference with the cell wall synthesis, damage as a result of which cell permeability may be altered or they may disorganize the lipoprotein leading to the cell death.

(ii) Deactivation of various cellular enzymes, which plays a vital role in different metabolic pathways of these microorganisms ${ }^{38}$.

(iii) Denaturation of one or more proteins of the cell, as a result of which the normal cellular processes are impaired.

(iv) Formation of a hydrogen bond through the azomethine group with the active centre of cell constituents, resulting in interference with the normal cell process ${ }^{39}$.

From the observed cyclic voltammetric behaviour, the redox properties of copper ion, may also contribute to their inherent toxicity. For example, redox cycling between $\mathrm{Cu}(\mathrm{II})$ and $\mathrm{Cu}(\mathrm{I})$ can catalyze the production of highly reactive hydroxyl radicals, which can subsequently damage lipids, proteins, DNA and other biomolecules.

Several mechanisms may be responsible for the cytotoxic effect of the metal chelates. After penetration of the complex into the organism, the cellular oxygen oxidizes the cellular mercapto compounds (RSH), and the electron transfer process is mediated through the central $\mathrm{Cu}$ (II) ion of the complex. Probably, the intracellular $\mathrm{Cu}(\mathrm{II})$ complex undergoes reduction to $\mathrm{Cu}(\mathrm{I})$ complex by the different sulphydryl group-containing compounds(RSSR). The reduced $\mathrm{Cu}(\mathrm{I})$ complexes may catalyze the reduction of $\mathrm{O}_{2}$ to $\mathrm{O}_{2}^{-}$, while $\mathrm{Cu}$ (II) complexes may catalyze the dismutation of $\mathrm{O}_{2}^{-}$to $\mathrm{H}_{2} \mathrm{O}_{2}{ }^{2}$. In this situation, the $\mathrm{Cu}(\mathrm{I}) / \mathrm{Cu}(\mathrm{II})$ couple is involved as a redox center. It is known that by changing the ligand environment around the central copper ion, the redox potential of the couple can be significantly changed. The $\mathrm{O}_{2}^{-}$and $\mathrm{H}_{2} \mathrm{O}_{2}$ produced by such redox reactions cause cell toxicity by their potential oxidizing effect on vital cell components such as lipoic acid, etc. In addition, the reduced $\mathrm{Cu}(\mathrm{I})$ complex may inhibit DNA synthesis, energy, or ATP production by inhibition of mitochondrial respiration and destruction of cell viability.

The probable cytotoxic reactions can be outlined as follows:

$$
\begin{array}{lll}
\mathrm{Cu}(\mathrm{II}) \text { complex } & \mathrm{Cu}(\mathrm{I}) \text { complex } \\
(\text { inside the organ ism ) } & \text { (outside the organ is } \mathrm{m} \text { ) }
\end{array}
$$

Step:2

$$
\begin{aligned}
& \mathrm{Cu}(\mathrm{II}) \text { complex }+\mathrm{RSH} \stackrel{\mathrm{O}_{2}}{\longrightarrow} \mathrm{Cu}(\mathrm{I}) \text { complex }+ \text { RSSR } \\
& + \text { reduced oxygen } \\
& \text { containing radicals }
\end{aligned}
$$

Step $: 3$

$\mathrm{Cu}(\mathrm{I})$ complex $\stackrel{\text { DNA }}{\longrightarrow}$ inhibition of DNA synthesis

\section{Step:4

$\mathrm{Cu}(\mathrm{I})$ complex $\stackrel{\text { Phosphorylation }}{\longrightarrow} \begin{aligned} & \text { inhibition of ox idative } \\ & \text { phosphorylation }\end{aligned}$

Oxidation of thiol compounds by cellular oxygen catalyzed by a copper complex was demonstrated by the fact that during the reaction of bis(thiosemicarbazone)copper(II) complexes with Ehrlich cells, the cells showed a stimulated rate of oxygen consumption ${ }^{40}$. Here, it is worth mentioning that such oxidation of cellular thiols through the catalytic role of copper is also assumed to be the key step of cytotoxic reactions in many anticancer drugs ${ }^{40}$.

\section{Powder XRD study}

Single crystals of the complexes under study could not be obtained because the metal complexes wear isolated as powder rather than single crystals, in addition to their insolubility in most organic solvents, thus no definitive structure can be described. X-ray powder diffraction patterns in the $10^{\circ}<2 \theta$ $<90^{\circ}$ of the compounds were carried in order to obtain an idea about the lattice dynamics of the compound. X-ray diffraction patterns of $\mathrm{CuL}^{1}$ complex was recorded between $10^{\circ}$ and $90^{\circ}(2 \theta)$ and is given in Figure 6 . The value of $(2 \theta)$, interplanar spacing $\mathrm{d}\left(\mathrm{A}^{\circ}\right)$, FWHM and the relative intensities of the compounds under study were compiled in Table 7 . The X-ray powder diffraction pattern throws light only on the fact that each solid represents a definite compound of a definite structure which is not contaminated with starting materials.

Figure 6 shows the $\mathrm{X}$-ray diffraction patterns of the $\mathrm{CuL}^{1}$ complex. $\mathrm{Cu}(\mathrm{II})$ complex shows sharp crystalline peaks. The crystallite size of the complex $\mathrm{d}_{\mathrm{XRD}}$ could be estimated from XRD patterns by applying full-width half maximum of the characteristic peak to Scherre's equation (1)

$$
\mathrm{d}_{\mathrm{XRD}}=0.9 \lambda / \mathrm{FWHM} \operatorname{Cos} \theta \text {--------------------------(1) }
$$

where $\lambda$ is the wavelength used, FWHM is the full width at half maxima and $\theta$ is the diffraction angle ${ }^{41}$. The $\mathrm{CuL}^{1}$ complex has the crystallite size of 50 $\mathrm{nm}$ respectively. It represents the mean size of every nanocrystallite complexes. All other complexes supports similar crystallite size pattern.

Comparing the X-ray diffraction pattern of the ligands and their copper complexes indicate that the interplanar spacing and the relative intensities are 
different which could be attributed to the complex formation. Furthermore, correlation of analytical, spectroscopic and magnetic data enables us to predict the possible structure for the copper complexes.

\section{CONCLUSION}

Novel tetradentate Schiff base ligands derived from Knoevenagel condensate $\beta$-ketoanilides (obtained from acetoacetanilide and substituted benzaldehydes) and their copper(II) complexes have been characterized by analytical and spectral techniques. From the electronic absorption spectra and the stoichiometric analysis, square-planar geometry was assigned for the synthesized complexes. The very low conductivity values indicate that all the complexes are non-electrolytes. From their magnetic susceptibility and ESR spectral data the monomeric nature of the complexes was confirmed. Redox couple of the copper complexes was assigned as quasi-reversible from their cyclic voltammetric data. From the antimicrobial screening observation, cyclic voltammetric behaviour and the available literature knowledge, the above possible ways to inhibit the antimicrobial growth using synthesised copper(II) complexes were explained. The redox properties of copper ion, the presence of $>\mathrm{C}=\mathrm{N}$ group, carboxylate moiety and also substituents are responsible for their increased antimicrobial activity. It is believed that the new derivatives can provide a wide choice and flexibility to change the structure in order to find a less toxic derivative with enhanced activity. From the XRD data, the $\mathrm{CuL}^{1}$ complex has the crystallite size of $50 \mathrm{~nm}$ respectively.

\section{ACKOWLEDGEMENTS}

The authors express their sincere thanks to the Head, Department of Chemistry, Principal and College Managing Board of VHNSN College, Virudhunagar for their constant encouragement and providing research facilities. NR and RJ thank the DST, New Delhi for financial assistance.

\section{REFERENCES}

1. P. Kamalakannan and D. Venkappayya, J. Inorg. Biochem. 21, 22, (2002).

2. M.C.R. Argüelles, S.M. Vazquez, P.T. Touceda, J.S. Matalobos, A.M.G. Deibe, M.G. Ferrari, G. Pelosi, C. Pelizzi and F. Zani, J. Inorg. Biochem. 101, 138, (2007).

3. E.M. Treshchalina, A.L. Konovalova, M.A. Presnov, L.F. Chapurina and N.I. Belichuk, Doklady Akademii Nauk. 248, 1273, (1979).

4. J.R.J. Sorenson, J Med Chem 19, 135, (1976).

5. D.H. Brown, A.J. Lewis, W.E. Smith and J.W. Teape, J. Med. Chem. 23, $729,(1980)$.

6. J.R.J. Sorenson, Chem in Britain, 1110, (1984).

7. J.R.J. Sorenson, Prog. Med. Chem. 26, 437, (1989).

8. M. Carcelli, P. Mazza, C. Pelizzi and F. Zani, Transition. Met. Chem. 57, 43, (1995).

9. A.E. Liberta and D.X. West, BioMetals, 5, 121, (1992).

10. K. Singh, M.S. Barwa and P. Tyagi, Euro J. Med. Chem. 42, 394, (2007).

11. J. Lv, T. Liu, S. Cai, X. Wang, L. Liu and Y. Wang, J. Inorg. Biochem. 100, 1888, (2006).
12. M.R. Parra, T. García, E. Lorenzo and F. Pariente, Biosensors and Bioelectronics, 22, 2675 and 2681, (2007).

13. R. Reiner, In Antibiotics-an introduction. Roche Scientific Services, Switzerland. 1, 21, (1982).

14. M.L. Harikumaran Nair, G. Mathew and M.R. Sudarasana Kumar, Indian J. Chem. 44A, 85, (2005).

15. C.G. Mohamed and Z.H. Abd El-Wahab, J. Therm. Anal. Calorim., 73 347, (2003).

16. P.B. Sreeja and M.R.P. Kurup, Spectrochim Acta A, 61, 331, (2005).

17. C. Jayabalakrishnan and K. Natarajan, Transition Met. Chem. 27, 75, (2002).

18. Z.H. Abd El-Wahab, M.M. Mashaly, A.A. Salman, B.A. El-Shetary and A.A. Faheim, Spectrochim. Acta, A 60, 2861, (2004).

19. W. Ference and A.W. Dziewulska, J. Therm. Anal. Calorim. 63, 865, (2001).

20. M.L. Hu, N.W. Zhu, X.H. Li and F. Chen, Cryst. Res. Technol. 39, 505, (2004).

21. A. Szorcsik, L. Nagy, L. Pellerito, T. Yamaguchi and K. Yoshida, J. Radioanal. Nucl. Chem. 256, 3, (2003).

22. A. Szorcsik, L. Nagy, J. Sletten, G. Szalontai, E. Kamu, T. Fiore, L. Pellerito and E. Kalman, J. Organomet. Chem. 689, 1145, (2004).

23. V.C. Wei, L.Y. Tuan and L.D. Zheng, Chin. J. Chem. 18, 35, (2000).

24. B.S. Garg, D.N. Kumar and M. Sarbhai, Spectrochim. Acta A 61, 141, (2005).

25. N.Raman, A. Kulandaisamy and C. Thangaraja, Transition Met. Chem. 28, 29 (2003)

26. A.B.P. Lever, Inorganic Electronic Spectroscopy, $2^{\text {nd }}$ Edn., Elsevier, New York (1968).

27. G. Maki, J. Chem. Phys. 28, 651, (1958).

28. O. Kahn, Adv. Inorg. Chem. 43, 197 (1995).

29. O. Kahn, Adv. Inorg. Chem. 43, 179, (1995).

30. R.K. Ray and G.B. Kaufiman, Inorg. Chim. Acta 173, 207, (1990).

31. M. Massacesi,D.G. Ponticelli, V.B. Addepalli and V.G. Krishnan, J. Mol. Struct. 48, 55, (1978).

32. M. Massacesi, K. Madhukar, B. Madhu, B.A. Sastry and G. Ponticelli, J. Phys. Soc. Jpn. 58, 336, (1989).

33. K.H. Reddy, P.S. Reddy and P.R. Babu, J. Inorg. Biochem. 77169 (1999).

34. Y. Anjaneyula and R.P. Rao, Synth. React. Inorg. Met.-Org. Chem. 16, 257, (1986).

35. N. Dharamaraj, P. Viswanathamurthi and K. Natarajan, Transition Met. Chem. 26, 105, (2001).

36. R. Malhota, S. Kumar and K.S. Dhindsa, Indian J. Chem. 32A, 457, (1993).

37. L. Mishra and V.K. Singh, Indian J. Chem. 32A, 446, (1993).

38. R.S. Satoskar and S.D. Bhandarkar, Pharmacology and Pharmacotherapeutics, $13^{\text {th }}$ Popular prakash private Ltd, Bombay, 552, (1933).

39. A.K. Das (Ed.), Medicinal Aspects of Bioinorganic Chemistry, Chap.3, CBS, Shahdara, Delhi, (1990).

40. H. Abd El-Wahab, Spectrochim. Acta A 67, 25, (2007). 